\title{
The Substantia Nigra Pars Compacta and Temporal Processing
}

\author{
Marjan Jahanshahi, ${ }^{1}$ Catherine R. G. Jones, ${ }^{1}$ Georg Dirnberger, ${ }^{1}$ and Christopher D. Frith ${ }^{2}$ \\ ${ }^{1}$ Sobell Department of Motor Neuroscience and Movement Disorders and ${ }^{2}$ Wellcome Department of Imaging Neuroscience, Institute of Neurology, London \\ WC1N 3BG, United Kingdom
}

\begin{abstract}
The basal ganglia and cerebellum are considered to play a role in timing, although their differential roles in timing remain unclear. It has been proposed that the timing of short milliseconds-range intervals involves the cerebellum, whereas longer seconds-range intervals engage the basal ganglia (Ivry, 1996). We tested this hypothesis using positron emission tomography to measure regional cerebral blood flow in eight right-handed males during estimation and reproduction of long and short intervals. Subjects performed three tasks: (1) reproduction of a short $500 \mathrm{~ms}$ interval, (2) reproduction of a long $2 \mathrm{~s}$ interval, and (3) a control simple reaction time (RT) task. We compared the two time reproduction tasks with the control RT task to investigate activity associated with temporal processing once additional cognitive, motor, or sensory processing was controlled. We found foci in the left substantia nigra and the left lateral premotor cortex to be significantly more activated in the time reproduction tasks than the control RT task. The left caudate nucleus and right cerebellum were more active in the short relative to the long interval, whereas greater activation of the right putamen and right cerebellum occurred in the long rather than the short interval. These results suggest that the basal ganglia and the cerebellum are engaged by reproduction of both long and short intervals but play different roles. The fundamental role of the substantia nigra in temporal processing is discussed in relation to previous animal lesion studies and evidence for the modulating influence of dopamine on temporal processing.
\end{abstract}

Key words: basal ganglia; cerebellum; dopaminergic; cognitive; cortex; premotor

\section{Introduction}

Timing is a fundamental feature of human movement, perception, and cognition. Experimental studies on clinical populations have provided evidence that both the basal ganglia and cerebellum play a role in temporal processing. Patients with cerebellar disease have difficulty performing tasks requiring precise motor timing (e.g., repetitive tapping at specific frequencies) and perceptual (nonmotor) timing (e.g., discriminating the duration of two intervals) (Ivry et al., 1988; Ivry and Keele, 1989; Mangels et al., 1998). Patients with Parkinson's disease (PD) also display significant deficits in both motor (Pastor et al., 1992b; O'Boyle et al., 1996; Harrington et al., 1998a) and perceptual (Pastor et al., 1992a; Harrington et al., 1998a) timing tasks, deficits that are ameliorated with dopaminergic medication (Pastor et al., 1992a,b; O'Boyle et al., 1996; Malapani et al., 1998). Consequently, it has been proposed that the principal anatomical structures affected by these disorders, namely the cerebellum and basal

\footnotetext{
Received June 16, 2006; revised 0ct. 13, 2006; accepted 0ct. 18, 2006.

This work was supported by grants from the Brain Research Trust and the Centre for Consciousness Studies, University of Arizona. C.R.G.J. was funded by the Brain Research Trust and the Medical Research Council. M.J., G.D., and C.D.F. were funded by the Wellcome Trust.

Correspondence should be addressed to M. Jahanshahi, Cognitive Motor Neuroscience Group, Sobell Department of Motor Neuroscience and Movement Disorders, Institute of Neurology, Queen Square, London WC1N 3BG, UK. E-mail:m.jahanshahi@ion.ucl.ac.uk.

C. R. G. Jones's present address: Behavioural and Brain Sciences Unit, Institute of Child Health, London WC1N 1EH, UK.

G. Dirnberger's present address: Department of Neurology, Medical University of Vienna, A-1090 Vienna, Austria. DOI:10.1523/JNEUROSCI.2540-06.2006

Copyright $\odot 2006$ Society for Neuroscience $\quad$ 0270-6474/06/2612266-09\$15.00/0
}

ganglia, must be crucial to the effective running of an "internal clock" (Ivry, 1996). The involvement of the cerebellum and basal ganglia in motor and perceptual timing has been confirmed by imaging studies using various timing tasks, such as the repetitive tapping paradigm (Lejeune et al., 1997; Rao et al., 1997; Rubia et al., 1998), duration discrimination (Jueptner et al., 1995; Maquet et al., 1996; Rao et al., 2001; Ferrandez et al., 2003; Lewis and Miall, 2003a, 2006; Nenadic et al., 2003; Harrington et al., 2004a), velocity discrimination (Jueptner et al., 1996), rhythm discrimination (Schubotz et al., 2000; Schubotz and von Cramon, 2001), temporal discrimination (Pastor et al., 2006), and time production and reproduction (Brunia et al., 2000; Tracy et al., 2000; Lewis and Miall, 2002, 2006; Macar et al., 2002, 2004; Pouthas et al., 2005).

What remains unclear is what the specific role of the cerebellum and basal ganglia in timing may be. Ivry (1996) has suggested that the cerebellum controls the timing of short intervals (milliseconds range), whereas the basal ganglia are involved in the timing of long intervals (seconds range). This hypothesis is consistent with the commonly held view that the role of the cerebellum in the precise timing of short intervals reflects its role in motor coordination and movement control. The primary aim of this study was to test Ivry's (1996) hypothesis by directly comparing neural activity elicited by milliseconds- and seconds-range time reproduction. Perceiving and reproducing a time interval involves a network of brain areas engaged in supportive processes such as attention and memory, with the hypothesized "clock"like structures being only one component. Therefore, we also 
compared the two timing tasks with a control reaction time (RT) task, revealing neural activity specific to temporal processing.

\section{Materials and Methods Participants}

Eight male, right-handed volunteers with an average \pm SD age of $27.5 \pm$ 6.8 years (range, $19-40$ years) participated in the study. All subjects were healthy and without a history of neurological or psychiatric disease or head injury. The extent of right handedness was measured with a modified version of the Handedness Inventory (Oldfield, 1971). The subjects were all strongly right handed (mean $\pm \mathrm{SD}, 94.7 \pm 8.07$ ). Estimates of verbal intelligence quotient (IQ) were obtained from the National Adult Reading Test (Nelson, 1982). The average \pm SD score was $119 \pm 4.24$, indicating that all of the sample had IQs in the high average range. The study had the approval of the Joint Medical Ethics Committee of the National Hospital for Neurology and Neurosurgery and the Institute of Neurology. Written, informed consent was obtained from all subjects before the experiment.

\section{Design}

The study used a within-subject repeated-measures design. There were three experimental conditions: short-interval reproduction (SHORT), long-interval reproduction (LONG), and a control reaction time task. During the positron emission tomography (PET) scan, each condition was repeated four times, resulting in 12 scans per subject. The order of presentation was pseudorandomized across subjects using a Latin Square procedure.

The intervals chosen to represent "short" and "long" time reproduction were based on previous literature. Michon (1985) described $500 \mathrm{~ms}$ as the cutoff between interval estimation that is highly perceptual and interval estimation that is cognitively mediated. The $500 \mathrm{~ms}$ interval was considered to be suitably short, without the risk of eliciting simple reaction times. The interval of $2000 \mathrm{~ms}$ was considered long enough to qualify for Ivry's (1996) definition of a long interval as well as requiring cognitive mediation, with little risk of more elaborate strategy use or waning attention.

\section{Procedure}

\section{Experimental conditions}

Approximately $30 \mathrm{~min}$ before the PET scanning, the subjects practiced the three experimental tasks, each twice. The purpose of the practice blocks was to ensure that the subjects understood the requirements of the tasks and that they had reached a criterion level of accuracy on the time estimation conditions. For the short-interval condition, the mean of each practice trial was required to be within $100 \mathrm{~ms}$ of the target (i.e., $\pm 100 \mathrm{~ms}$ ), and, for the long-interval condition, the mean of each practice trial was to be within $400 \mathrm{~ms}$ of the target (i.e., $\pm 400 \mathrm{~ms}$ ). All subjects achieved criterion performance within the two blocks of practice trials.

Reproduction of a SHORT interval. Subjects were instructed to reproduce a short interval. The duration of the interval was $500 \mathrm{~ms}$, although the precise value was not explicitly communicated to the subjects. First, the duration of the interval was demonstrated to the subject, with presentation of two tones $(1000 \mathrm{~Hz}, 50 \mathrm{~ms}$ duration) marking its onset and offset. After five presentations of the interval, the subjects began a practice block. They were told that a tone would be presented that would mark the beginning of the short interval. They should immediately start estimating and reproducing the duration of the target interval and press the response button to mark its end. A block consisted of 50 trials. The intertone intervals varied between 3 and $4 \mathrm{~s}$ (mean of $3.5 \mathrm{~s}$ ). During the scan, each experimental block was preceded by three demonstrations of the duration of the target interval. This allowed subjects to reacquaint themselves with the target interval, encouraging optimal performance.

Reproduction of a LONG interval. Subjects were asked to reproduce a long interval. The duration of the interval was $2000 \mathrm{~ms}$, but this value was not explicitly communicated to the subject. The instructions and procedures were identical to those used for the short intervals.
Control reaction time task. This was a simple reaction time task. Subjects were instructed that, when a tone was presented, they should press the response button as quickly as possible in response to it. The reaction time condition matched the time estimation conditions in terms of the characteristic of the tone $(1000 \mathrm{~Hz}, 50 \mathrm{~ms}$ duration), the number of responses (50 trials), and the intertone intervals (3-4 s, mean of $3.5 \mathrm{~s}$ ).

The same response box was used in all three conditions. It measured $15 \times 8 \times 5 \mathrm{~cm}$ and had two response buttons (diameter of $2.5 \mathrm{~cm}$ ) positioned at either end. Subjects were instructed to respond with the same button and to ignore the second button. All responses were made with the right index finger. The response times were recorded to the nearest millisecond. During the practice trials, the tones were presented through a loudspeaker. When the subjects were in the scanner, the tones were presented through earphones, with adjustment made for optimal volume for each subject.

\section{Measurement of regional cerebral blood flow with PET}

Measurements of regional cerebral blood flow (rCBF) were obtained using a Siemens/CPS ECAT EXACT HR + PET scanner (Siemans/CTI, Knoxville, TN) in three-dimensional (3D) mode with interdetector collimating septa retracted. The axial field of view was $155 \mathrm{~mm}$, providing whole-brain coverage, including the cerebellum. For each measurement, $\sim 9 \mathrm{mCi}$ of $\mathrm{H}_{2}{ }^{15} \mathrm{O}$ was given intravenously through a forearm cannula over $20 \mathrm{~s}$, followed by a $20 \mathrm{~s}$ saline flush. rCBF data were collected over a $90 \mathrm{~s}$ activation period that began $5 \mathrm{~s}$ before the rising phase of radioactivity in the head. Twelve sets of data were collected (four sets of data of each of the three tasks), with an 8 min rest period between successive scans to allow for the radioactivity to decay. A transmission scan was performed before data collection to correct for attenuation effects. The images were reconstructed using 3D filtered back projection into 63 transverse planes and into a $128 \times 128$ pixel image matrix (pixel size, $2.4 \times 2.1 \times 2.1 \mathrm{~mm}$ ), with a resolution of $6 \mathrm{~mm}$ at full-width halfmaximum. Additionally, T1-weighted structural magnetic resonance imaging (MRI) scans were obtained for each subject using a Siemens (Erlangen, Germany) Magnetom VISION MRI scanner operating at 2 tesla.

Subsequent reconstruction and analysis of the images was undertaken using statistical parametric mapping software (SPM99; Wellcome Department of Imaging Neuroscience, London, UK; http://www.fil.ion. ucl.ac.uk/spm) executed in Matlab (MathWorks, Sherbon, MA). For each subject, the 12 scans were realigned to the first to adjust for the effects of any head movements (Friston et al., 1995a). All images were then spatially normalized (Friston et al., 1995a) into a template based on the Montreal Neurological Institute (MNI) reference brain that conforms to a standard anatomical space (Talairach and Tournoux, 1988). An isotropic Gaussian kernel of $12 \mathrm{~mm}$ full-width at half-maximum was then used to smooth the images. This accommodated for intersubject differences in anatomy, increased the signal-to-noise ratio, and allows for subsequent statistical inference using Gaussian random field theory.

The general linear model was used to estimate condition and subject effects at each voxel point in the brain (Friston et al., 1995b). Scan-toscan differences in global blood flow were modeled as a confounding covariate. Hypotheses about regionally specific condition effects were tested using linear contrasts to compare condition differences in the mean relative $\mathrm{rCBF}$ at each voxel. For each contrast, a $t$ statistic was computed for every voxel to form a statistical parametric map (SPM $\{t\}$ ). The SPM $\{t\}$ values were then transformed to the unit normal distribution to give an SPM $\{z\}$. The level of significance was set to $p<0.05$, corrected for multiple comparisons. Cortical and subcortical areas, for which we had an a priori hypothesis, were reported at $p<0.001$, uncorrected. To reduce the chance of false-positive activations, conjunction analysis was used to check that areas that were important to our hypothesis were present in all or a majority of subjects (Friston et al., 1999). True regions of activation are likely to be present in a majority of subjects, whereas noise is unlikely to show a systematic pattern across subjects in a well designed experiment.

To identify regions of the brain specific to short- and long-interval reproduction, respectively, simple SHORT $>$ LONG and LONG > SHORT contrasts were used. Areas of the brain specific to time repro- 

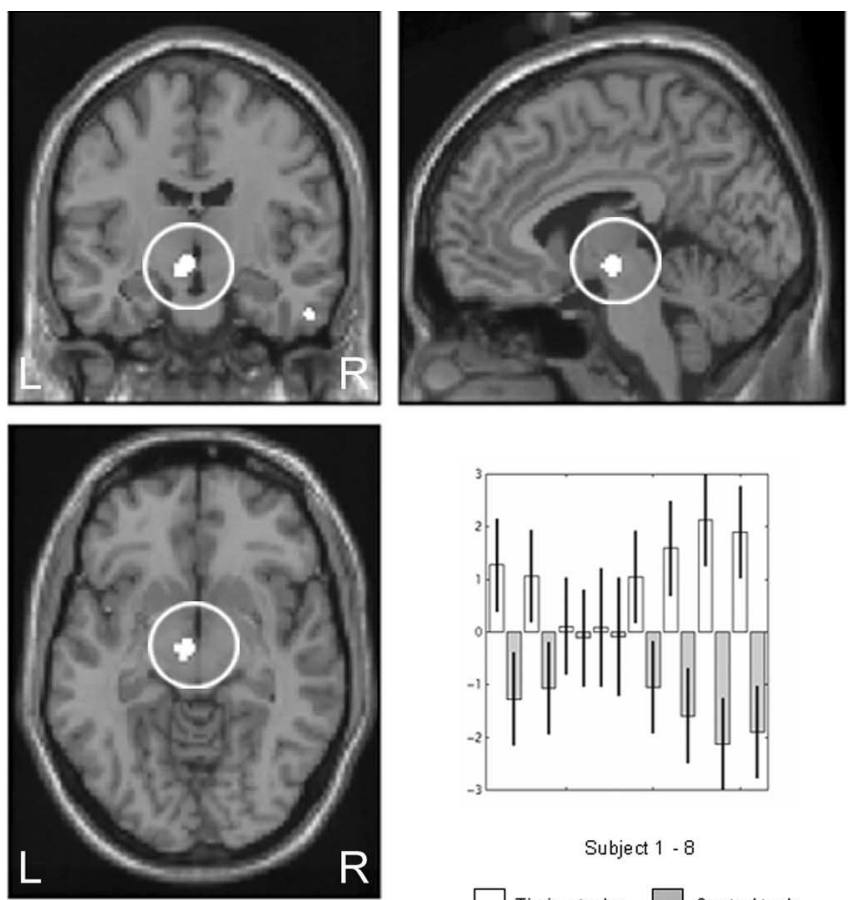

Timing tasks $\square$ Control task
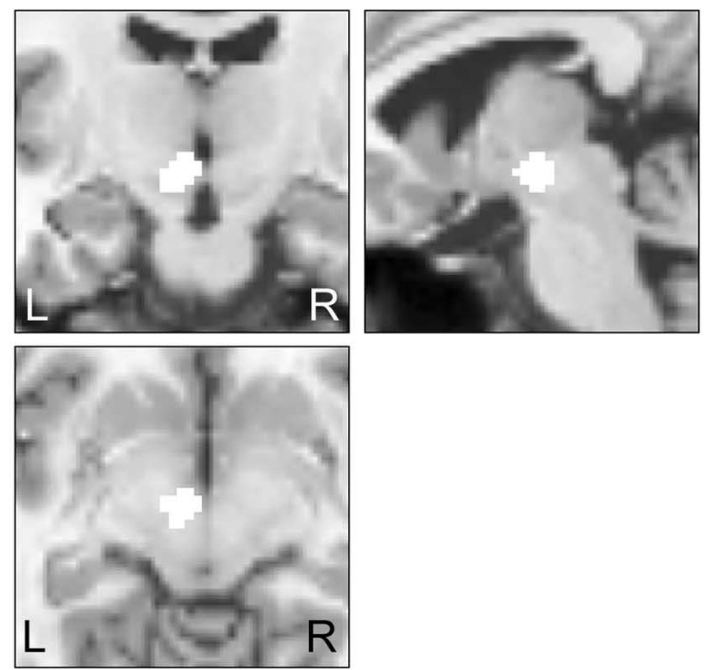

Figure 1. Time reproduction $>$ control RT: left SNc. Left substantia nigra pars compacta activation $[(-4,-12,-8)]$ greater in the time reproduction tasks (SHORT + LONG) than the control reaction time task. Activations are shown on the MNI reference brain, on sagittal, coronal, and horizontal views. Parameter estimates for the left substantia nigra pars compacta showing increased activity during timing tasks compared with the control reaction time task across all subjects. Significant at $p>0.001$, uncorrected. L, Left; R, right.

duction were elicited in a (SHORT LONG) $>$ RT comparison. Anatomical localization of the significant voxel coordinates was determined by rendering them onto the subjects' structural MRIs and the MNI reference brain and with reference to the atlas of Durvenoy (1991). In addition, the standard stereotaxic atlas of Talairach and Tournoux (1988) was used for additional reference, particularly to aid in determining Brodmann areas (BA). Detailed information about the location of voxels in the cerebellum was gained with reference to an MRI atlas of the cerebellum (Schmahmann et al., 2000). For the primary motor cortex and somatosensory area, probabilistic cytoarchitectonic atlases have been produced, and these were also used (Geyer et al., 1996, 1999, 2000).
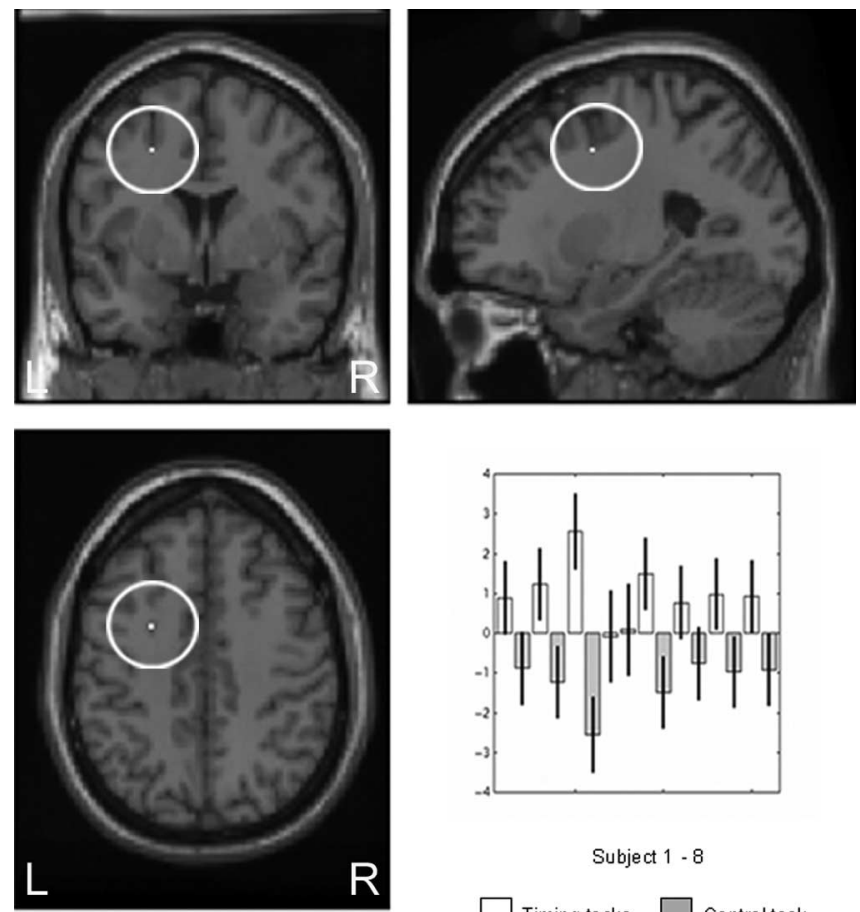

Subject $1-8$

Timing tasks Control task

Figure 2. Time reproduction $>$ control RT: left premotor cortex. Left premotor cortex activation $[(-24,2,44)]$ greater in the time reproduction tasks (SHORT + LONG) than the control reaction time task. Activations are shown on the MNI reference brain, on sagittal, coronal, and horizontal views. Parameter estimates for the left premotor cortex showing increased activity during timing tasks compared with the control reaction time task across all subjects. Significant at $p>0.001$, uncorrected. $L$, Left; $R$, right.

\section{Results}

\section{Behavioral performance}

For the two practice blocks, the average reproduced duration of the short interval was $555.21 \mathrm{~ms}$ (median \pm SD, $568.50 \pm 26.10$ ), and the long interval was $2027.36 \mathrm{~ms}$ (median \pm SD, $2036 \pm$ 81.89 ). Both of these values indicate that subjects were accurate in time reproduction and had reached the required level of competence before the scanning. The mean reaction time across the two practice blocks was $209.29 \mathrm{~ms}$ (median $\pm \mathrm{SD}, 209.00 \pm 36.59$ ). During scanning, the mean reproduced duration for the short interval was $561.96 \mathrm{~ms}$ (median $\pm \mathrm{SD}, 568.75 \pm 68.47$ ) and for the long interval was 2065.86 (median \pm SD, $2107.25 \pm 110.30$ ). The mean reaction time was 202.14 (median \pm SD, $184.50 \pm$ 44.05). Once again, the subjects maintained a high degree of accuracy in time estimation and reproduction for both the long and short intervals.

\section{PET results}

Time reproduction tasks versus control $R T$ task

A midbrain focus corresponding to the region of the left substantia nigra and red nucleus [coordinates shown as $(x, y, z)$ throughout; $(-4,-12,-8), Z=3.39, p=0.0001$, uncorrected; with an additional focus at $(-14,-18,-2), Z=2.45, p=0.007$, uncorrected] and the left lateral premotor cortex (LPMC) [BA $6(-24$, $2,44), Z=3.14, p=0.001$, uncorrected; with an additional focus at $(-22,10,38), Z=2.96, p=0.002$, uncorrected) were more activated during the time reproduction tasks than the RT task. The results are shown in Figures 1 and Figure 2. The subcortical coordinate plotted in Figure 1 is anatomically very close to both the red nucleus and the substantia nigra (Oikawa et al., 2002). 
Table 1. Areas of greater activation with the SHORT interval reproduction task compared with the LONG interval reproduction task

\begin{tabular}{|c|c|c|c|c|c|c|}
\hline & \multirow[b]{2}{*}{ BA } & \multicolumn{3}{|c|}{ MNI coordinates of peak activation } & \multirow[b]{2}{*}{ Z value of peak activation } & \multirow[b]{2}{*}{$p$ value* } \\
\hline & & $x$ & $y$ & $z$ & & \\
\hline \multicolumn{7}{|l|}{ Frontal cortex } \\
\hline L anterior cingulate & 32 & -2 & 40 & 8 & 4.80 & $0.025^{* *}$ \\
\hline R superior frontal gyrus & 8 & 10 & 46 & 52 & 3.99 & $<0.001$ \\
\hline$R$ superior and mesial frontal gyrus & $6 / 8$ & 6 & 38 & 60 & 3.74 & $<0.001$ \\
\hline L middle frontal gyrus & 8 & -40 & 18 & 44 & 3.79 & $<0.001$ \\
\hline L superior frontal gyrus & 8 & -12 & 48 & 44 & 3.71 & $<0.001$ \\
\hline L superior frontal gyrus & 10 & -18 & 54 & 24 & 3.54 & $<0.001$ \\
\hline R superior and mesial frontal gyrus & $9 / 10$ & 8 & 56 & 24 & 3.18 & 0.001 \\
\hline \multicolumn{7}{|l|}{ Temporal cortex } \\
\hline Lmiddle frontal gyrus & 21 & -58 & -24 & -12 & 4.21 & $<0.001$ \\
\hline L superior temporal cortex & 22 & -48 & -24 & -2 & 3.52 & $<0.001$ \\
\hline \multicolumn{7}{|l|}{ Basal ganglia } \\
\hline L caudate nucleus & & -14 & -10 & 20 & 3.15 & 0.001 \\
\hline \multicolumn{7}{|l|}{ Cerebellum } \\
\hline R cerebellar hemisphere (Crus I) & & 36 & -74 & -38 & 3.12 & 0.001 \\
\hline
\end{tabular}
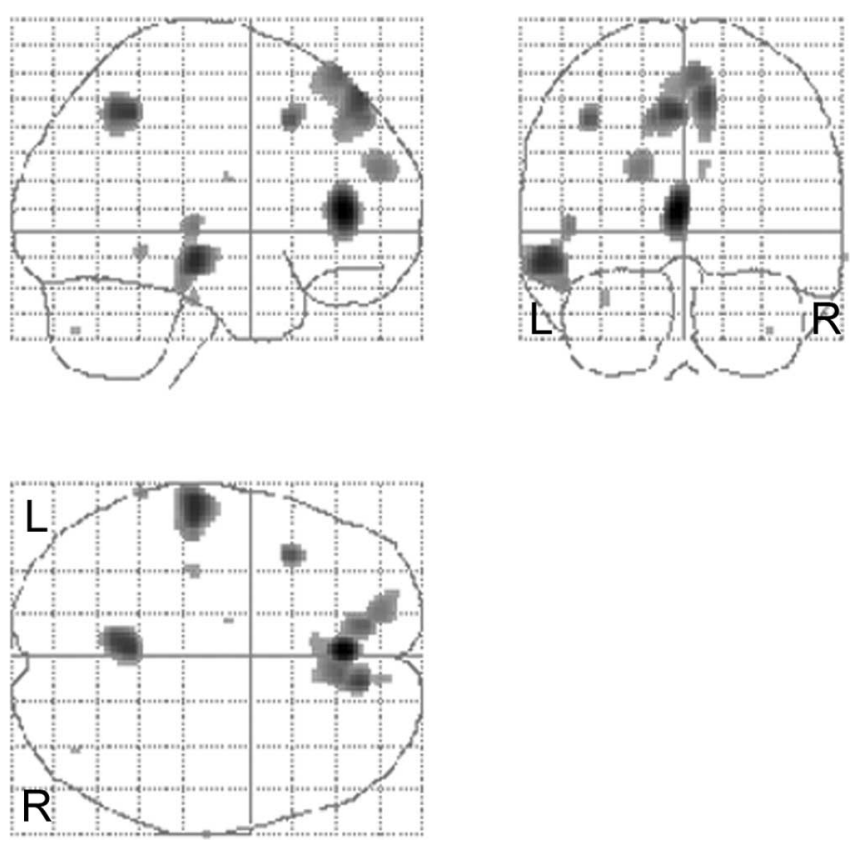

Figure 3. SHORT $>$ LONG. Results are displayed as statistical parametric maps in sagittal, coronal, and transverse projections in stereotactic space. Significant at $p>0.001$, uncorrected. $L$, Left; $R$, right.

After consultation with experts in basal ganglia and midbrain anatomy as well as drawing on theoretical understanding of the role of the substantia nigra in temporal processing, we propose that this region approximates the left substantia nigra pars compacta $(\mathrm{SNc})$. Given the potential theoretical interest in this finding, we further explored the activation by conducting a conjunction analysis of the two timing tasks, i.e., a conjunction analysis was performed on the (short-interval reproduction $>\mathrm{RT}$ ) and (long-interval reproduction $>\mathrm{RT}$ ) comparisons. This analysis also showed activation of the $\mathrm{SNc}[(-6,-12,-8) ; Z=3.36 ; p=$ 0.0001, uncorrected]. Furthermore, a conjunction analysis performed across all subjects (for the time reproduction tasks $>$ RT comparison) showed that activation of the left SNc was common to all subjects $[(-14,-16,-4), Z=3.59, p=0.0001$, uncorrected; with subfoci, $(-2,-6,-6), Z=3.58, p=0.0001$, uncorrected and $(-4,-14,-12), Z=3.52, p=0.0001$, uncorrected]. The plotted parameter estimates (reflecting the adjusted $\mathrm{rCBF}$ values) indicate that increased $\mathrm{rCBF}$ was observed for the time reproduction tasks compared with the control condition, for each subject. Similarly, the left lateral premotor cortex activation (Fig. 2) survived the conjunction analysis, indicating that it was active for each subject $[(-28,4,44) ; Z=3.46$; $p=0.0001$, uncorrected]. The parameter estimates indicate that increased $\mathrm{rCBF}$ was observed in the time reproduction tasks compared with the control RT task, for each subject with the exception of subject 4 .

Relative to the time reproduction tasks, the only area that showed significantly greater activation during the RT task was the right precuneus $[\mathrm{BA} 7,(6,-72,56) ; Z=4.75 ; p=0.009$ cluster and $p=0.030$ voxel $]$.

\section{SHORT > LONG interval reproduction}

This contrast elicited significant activation in the left anterior cingulate (BA 32), right superior frontal gyrus, spreading mesially (BA 6/8), the left middle frontal gyrus (BA 8), the left superior frontal gyrus (BA 8 and 10), the right superior and mesial frontal gyrus (BA 9/10), the left middle temporal gyrus (BA 21), and left superior temporal gyrus (BA 22). Subcortically, activation was observed in the left caudate nucleus and in the right cerebellar hemisphere. The results are presented in Table 1 and illustrated in Figures 3 and 4 . Figure 4 illustrates the left caudate nucleus and right cerebellar hemisphere activation. The conjunction analysis revealed significant left caudate activation $[(-12,-8,22 ; Z=$ 3.60; $p=0.0001]$ in an analogous location, indicating that the finding is robust across all subjects. In addition, the plotted parameter estimates indicate that the neural activity in this area is higher in the SHORT than the LONG condition across all subjects. The conjunction analysis for the right cerebellar hemisphere also revealed significant activation in a similar region $[(40$, $-72,-42) ; Z=3.38 ; p=0.0001]$. Parameter estimates illustrated that the right cerebellar hemisphere activation was greater in the SHORT than LONG condition for all subjects.

\section{LONG $>$ SHORT interval reproduction}

This contrast produced significant $\mathrm{rCBF}$ increases in the right superior parietal cortex (BA 7), lateral premotor cortex (BA 6) bilaterally, right supplementary motor area (SMA) (medial BA 6), the right inferior parietal (BA 40) cortex, the right cuneus (BA 17 ), the right primary motor cortex (BA 4), the right dorsolateral prefrontal cortex (DLPFC) (BA 9/46 and 10/46), the right putamen/insula border, and the right cerebellar hemisphere. The results are presented in Table 2 and illustrated in Figures 5 and 6. 
The activation for the right putamen/insula border is illustrated in Figure 6 and survived the conjunction analysis $[(42,6$, $4) ; Z=3.22 ; p=0.001]$. The area of activation extends from the insula into the putamen. The plot of parameter estimates showed that this area was more active in the LONG than SHORT condition for all participants except subject 1 . The right cerebellar hemisphere, plotted in Figure 6, survived the conjunction analysis across all subjects $[(48,-64,-22 ; Z=3.40 ; p=$ $0.0001]$, and the plotted parameter estimates showed that the area was more active in the LONG than SHORT condition in six of the eight subjects, with limited discernable difference in the other two subjects.

\section{Discussion}

We tested Ivry's (1996) hypothesis that the cerebellum is involved in the timing of short (milliseconds range) intervals, whereas the basal ganglia mediate the timing of long (seconds range) intervals. The results did not support the hypothesis because both structures were activated in the timing of both intervals. The timing tasks $>$ control RT contrast identified timing-specific activations in left $\mathrm{SNc}$ and left LPMC. This suggests the basal ganglia and its cortical projections play a more fundamental role in temporal processing than the cerebellum.

\section{Time reproduction activates the motor frontostriatal circuit}

A recent review discusses the relationship between RT and temporal processing (MacDonald and Meck, 2004). It has been suggested that RT protocols with a "preparatory" signal/interval before the cue to respond may share neural substrates with temporal processing tasks. However, the current RT task used an unwarned stimulus-response paradigm. The left SNc and left LPMC were identified as areas specific to time reproduction once additional processes, such as attention, tone anticipation and motor preparation, response initiation, and motor execution, were controlled. The symptoms of PD manifest after the degeneration of dopamine-producing neurons in the $\mathrm{SNc}$ (Kish et al., 1988), and the moderating effect of dopamine on timing is well documented (Pastor et al., 1992a,b; Meck, 1996; O'Boyle et al., 1996). Lesioning the left SNc in the rat causes temporal deficits (Matell et al., 2000), which levodopa improves (Meck, 1996, 2006). Functional MRI (fMRI) has revealed that unpredictability of task order and random timing activate substantia nigra (Dreher and Grafman, 2002), and neurons in the SNc show a depression in firing when an expected and time-predicted reward is not delivered (Hollerman and Schultz, 1998).

The striatal beat frequency (SBF) model (Matell and Meck, uncorrected. L, Left; R, right. reproduction task b
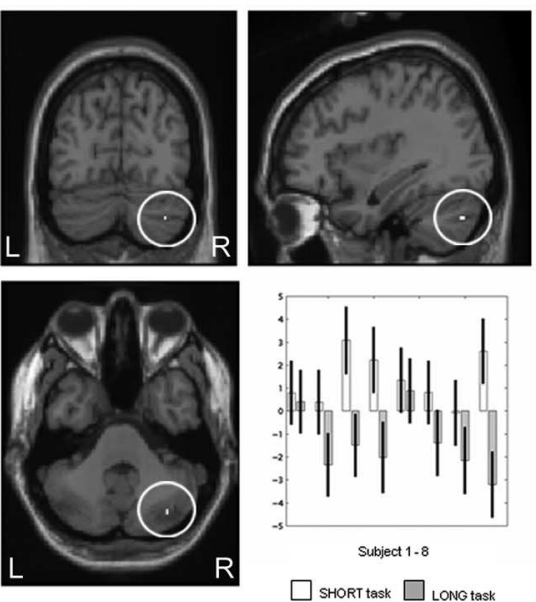

Figure 4. SHORT $>$ LONG: left caudate nucleus and right cerebellar hemisphere. $\boldsymbol{a}$, Left caudate nucleus $[(-14,-10,20)]$ activation greater in the SHORT reproduction task than in the LONG reproduction task. Parameter estimates showing mean activation for each subject are also displayed. $\boldsymbol{b}$, Right cerebellar hemisphere $[(36,-74,-38)]$ activation greater in the SHORT reproduction task than in the LONG reproduction task. Parameter estimates showing mean activation for each subject are also displayed. Activations are shown on the MNI reference brain, on sagittal, coronal, and horizontal views. Significant at $p>0.001$,

Table 2. Areas of greater activation with the LONG interval reproduction task compared with the SHORT interval

\begin{tabular}{|c|c|c|c|c|c|c|}
\hline & \multirow[b]{2}{*}{$B A$} & \multicolumn{3}{|c|}{$\begin{array}{l}\text { MNI coordinates of peak } \\
\text { activation }\end{array}$} & \multirow{2}{*}{$\begin{array}{l}Z \text { value of peak } \\
\text { activation }\end{array}$} & \multirow[b]{2}{*}{$p$ value $^{*}$} \\
\hline & & $x$ & $y$ & $Z$ & & \\
\hline \multicolumn{7}{|l|}{ Frontal cortex } \\
\hline L lateral premotor cortex & 6 & -54 & -2 & 42 & 4.59 & $<0.001$ \\
\hline L lateral premotor cortex & 6 & -56 & 8 & 8 & 4.49 & $<0.001$ \\
\hline RSMA & Medial 6 & 2 & -6 & 74 & 4.35 & $<0.001$ \\
\hline R primary motor cortex & 4 & 48 & -8 & 44 & 3.92 & $<0.001$ \\
\hline R lateral premotor cortex & 6 & 58 & 2 & 46 & 3.48 & $<0.001$ \\
\hline R somatosensory area & 3 & 54 & -16 & 38 & 3.25 & $<0.001$ \\
\hline $\mathrm{R}$ dorsolateral prefrontal cortex & $10 / 46$ & 34 & 46 & 10 & 3.82 & $<0.001$ \\
\hline R dorsolateral prefrontal cortex & $9 / 46$ & 38 & 32 & 28 & 3.40 & $<0.001$ \\
\hline R lateral premotor cortex & 6 & 64 & 4 & 16 & 3.23 & 0.001 \\
\hline \multicolumn{7}{|l|}{ Parietal cortex } \\
\hline R superior parietal cortex & 7 & 18 & -74 & 52 & 4.74 & $0.033^{* *}$ \\
\hline \multicolumn{7}{|l|}{ R inferior parietal cortex (intraparietal } \\
\hline sulcus/angular gyrus) & 40 & 42 & -52 & 50 & 4.26 & $<0.001$ \\
\hline \multicolumn{7}{|l|}{ Occipital gyrus } \\
\hline R cuneus & 17 & 10 & -90 & 6 & 3.95 & $<0.001$ \\
\hline \multicolumn{7}{|l|}{ Basal ganglia } \\
\hline R putamen/insula border & & 34 & 8 & 4 & 3.55 & $<0.001$ \\
\hline \multicolumn{7}{|l|}{ Cerebellum } \\
\hline R cerebellar hemisphere (lobule VI) & & 30 & -60 & -18 & 3.32 & $<0.001$ \\
\hline
\end{tabular}

${ }^{*} p>0.001$, uncorrected. ${ }^{* *} p>0.05$, familywise error. L, Left; $R$, right.

2000, 2004; Buhusi and Meck, 2005) proposes that detection of coincident neural activity encodes temporal durations. Cortical oscillatory activity is synchronized at trial onset, and the specific pattern of oscillatory activity at the time of reward or feedback can be detected by striatal spiny neurons. Dopaminergic activity in the SNc serves as a reinforcement signal and as a reset mechanism, resetting neurons and resynchronizing cortical oscillators (Matell and Meck, 2004). Thus, the SNc may act as a "perceptual starting gun," initiating the timing process, at the onset of an interval to be timed (Matell and Meck, 2000), a function essential in the current tasks.

The comparison of the timing tasks found the left caudate was 
active during milliseconds-range reproduction and the right putamen during seconds-range reproduction. Indeed, patients with PD show deficits in timing in the milliseconds- and seconds-range intervals (Pastor et al., 1992a,b; Harrington et al., 1998a; Malapani et al., 1998). Although the SBF model (Matell and Meck, 2000, 2004) specifies a key role for the striatum in producing temporal estimates, it does not outline individual roles for the putamen and caudate. Such differential activation likely mirrors the differing demands of milliseconds- and seconds-range timing, which also manifest at the cortical level. Lewis and Miall (2003a) compared the timing of 600 and $3000 \mathrm{~ms}$ intervals, but no differential basal ganglia activity was found. This may be because their stimuli contained visual subdivisions and these markers could influence temporal judgments. Pouthas et al. (2005) compared the timing of 450 and $3000 \mathrm{~ms}$ intervals. Seconds-range estimation was associated with right caudate activation; the SHORT > LONG contrast was not reported. Using a similar design to the current study, Hinton and Meck (2004) and Meck and Malapani (2004) reported activation of the putamen during time reproduction of 11 and $17 \mathrm{~s}$ durations. However, unraveling the differential patterns of activation of the caudate and putamen across studies is difficult because the tasks are different: visual versus auditory and discrimination versus reproduction. This requires additional investigation.

Our results suggest that the LPMC plays a primary role in temporal processing. Premotor activity has been found in fMRI studies of timing in which no motor component was present or was controlled (Schubotz et al., 2000; Rao et al., 2001; Ferrandez et al., 2003). Rao et al. (2001) suggested that the LPMC may have a working memory function, maintaining the standard interval, and clinical research has found that patients with premotor or SMA lesions display difficulties in rhythm reproduction from memory (Halsband et al., 1993). This explanation fits well with the current results because our task demanded that the interval be stored and maintained. Furthermore, the greater activation of the LPMC in the LONG $>$ SHORT contrast may reflect the greater demands of storage and maintenance of longer intervals.

\section{Cerebellar activation}

The absence of increased cerebellar activation in the timing tasks $>$ control task contrast suggests that cerebellar activation is not specific to explicit temporal processing but relates to other components of time reproduction.

Impairments in duration discrimination have been documented in patients with cerebellar pathology (Mangels et al., 1998; Casini and Ivry, 1999). However, these patients also showed impairment in frequency discrimination, suggesting a general perceptual or sensory deficit. None of the studies investigating performance of cerebellar patients on the repetitive tapping task have found impairment in accuracy, although increased variability has been reported (Ivry et al., 1988; Ivry and Keele, 1989; Harrington et al., 2004a). Harrington et al. (2004b) found greater clock-related variability in a subgroup of cerebellar patients, which correlated with working memory performance, and concluded that the cerebellum may process taskrelevant sensory or cognitive information as well as being important for motor output.

The hypothesis that the cerebellum may be important for peripheral, sensory aspects of temporal processing has also been proposed in functional imaging research (Penhune et al., 1998; Rao et al., 2001). Studies in which a tightly matched control task was used failed to find evidence of cerebellar activity (Lewis and Miall, 2002; Ferrandez et al., 2003; Macar et al., 2004; Pouthas et al., 2005), and cerebellar activation occurred mostly in motor timing tasks (Lejeune et al., 1997; Rao et al., 1997; Kawashima et al., 2000). Cerebellar activation
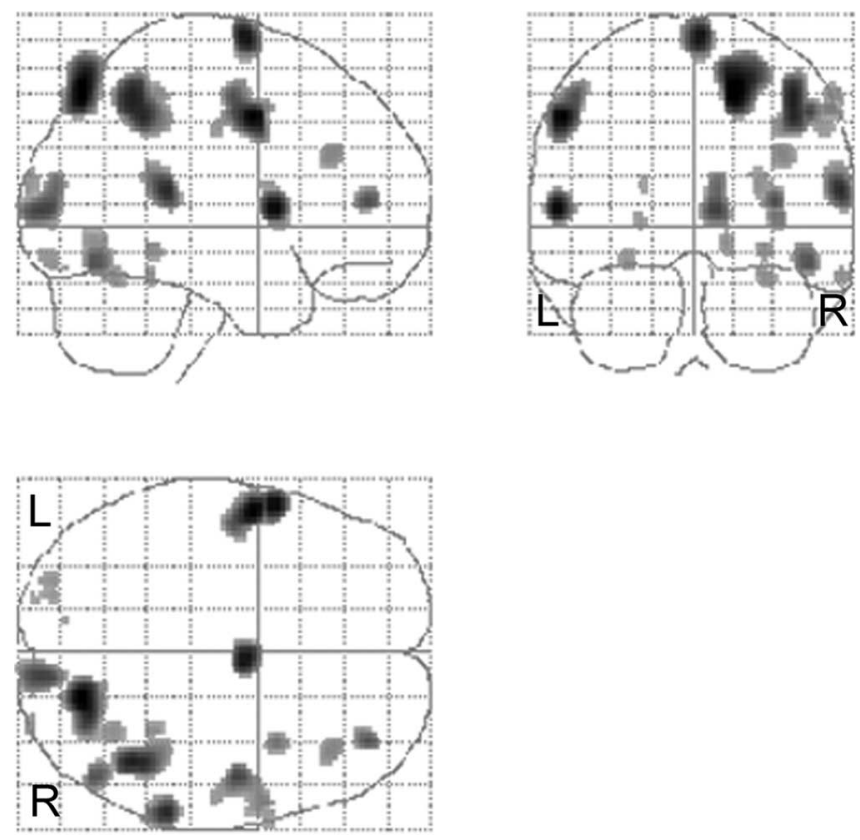

Figure 5. LONG > SHORT. Results are displayed as statistical parametric maps in sagittal, coronal, and transverse projections in stereotactic space. Significant at $p>0.001$, uncorrected. L, Left; R, right.

may reflect processes related to but not specific to timing that vary as a function of task demands, such that the core basal ganglia timing network integrates frontal and cerebellar activity when required. The cerebellar activation in the seconds range could be related to cognitive demands such as working memory rehearsal processes (Paulesu et al., 1993; Nichelli et al., 1996), whereas activation in the milliseconds range may reflect sensory processing or integration (Penhune et al., 1998; Rao et al., 2001).

\section{Cortical activation}

Whereas dopamine within the basal ganglia affects millisecond- and seconds-range timing, mesolimbocortical dopamine only affects seconds-range timing (Rammsayer, 1993, 1997). The differential patterns of cortical activation may relate to the way subjects timed the intervals. Michon (1985) suggested that processing of durations below $500 \mathrm{~ms}$ is highly perceptual and not under cognitive control. Lewis and Miall (2003b) proposed an "automatic" timing system concerning "predictable sub-second intervals defined by movement" and a seconds-range "cognitively controlled" timing system, depending on prefrontal and parietal regions. Indeed, in the present study, activation of prefrontal and parietal areas was greater for seconds-range timing. Subjects' reports suggested that millisecondsrange reproduction was implemented as an "intuitive" delayed reaction to the tone rather than as "deliberate" temporal processing. The anterior cingulate and prefrontal cortex are activated when holding competing responses in check (Pardo et al., 1990; Corbetta et al., 1991; Jahanshahi et al., 2000; Dirnberger et al., 2005). The short interval was close enough to reaction time that the anterior cingulate and frontal cortex may have been inhibiting an immediate response. Only the short interval activated the temporal cortex, which mirrors Lewis and Miall (2003a). This may reflect the greater salience of the tones, for example, subjects using a form of auditory template to reproduce the short interval. Similarly, Rao et al. (1997) have noted the importance of "auditory imagery" in temporal processing.

Cortical motor areas were more activated by the long interval. Functional imaging suggests that the SMA has a primary role in 
a
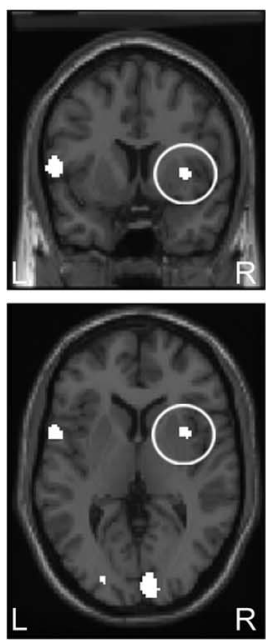

b
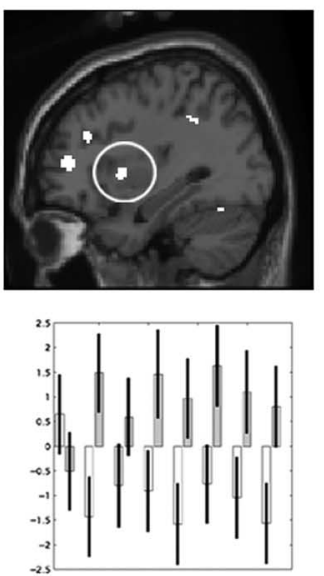

Subject $1-8$

$\square$ SHORT task $\square$ LONG task

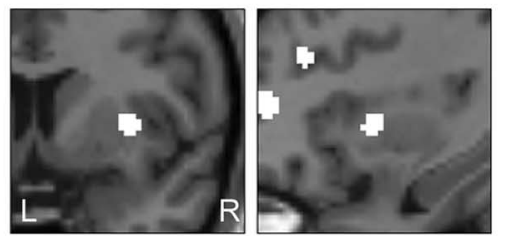

B.
C
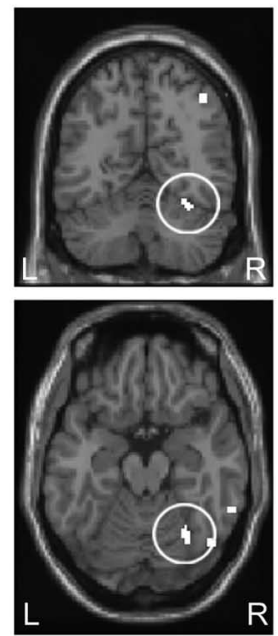
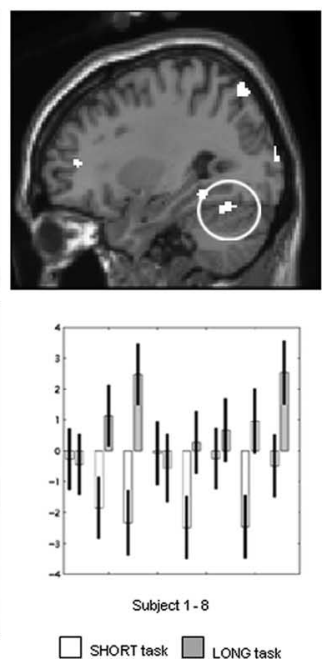

Figure 6. LONG $>$ SHORT: right putamen and right cerebellar hemisphere. $\boldsymbol{a}$, Right putamen $[(34,8,4)]$ activation greater in the LONG reproduction task than in the SHORT reproduction task. Parameter estimates showing mean activation for each subject are also displayed. $\boldsymbol{b}$, Right putamen $[(34,8,4)]$ activation greater in the LONG reproduction task than in the SHORT reproduction task. Enlarged image is shown. $\boldsymbol{c}$, Right cerebellar hemisphere $[(30,-60,-18)]$ activation greater in the LONG reproduction task than in the SHORT reproduction task. Parameter estimates showing mean activation for each subject are also displayed. Activations are shown on the MNI reference brain, on sagittal, coronal, and horizontal views. Significant at $p>0.001$, uncorrected. L, Left; R, right.

timing (Macar et al., 2002, 2004; Ferrandez et al., 2003), and motor cortical activation in timing tasks in which movement is controlled is common (Schubotz et al., 2000; Lewis and Miall, 2003a; Harrington et al., 2004a). The SMA is important in self-initiated or "willed" actions (Jahanshahi et al., 1995); and increased SMA activation could reflect demands on conscious temporal processing and response initiation strategies in seconds-range timing. Right DLPFC activation during seconds-range timing may indicate engagement of working memory processes (Rammsayer, 1997, 1999), consistent with previous research in which repetitive transcranial magnetic stimulation over right DLPFC disrupted time reproduction in the seconds-range only (Jones et al., 2004). For the LONG $>$ SHORT contrast, the right hemisphere was predominately activated, which reflects previous findings of right hemisphere dominance in temporal processing (Harrington et al., 1998b; Rao et al., 2001; Macar et al., 2002; Lewis and Miall, 2006).

The present results demonstrate the engagement of the basal ganglia, particularly the SNc, and their cortical projections in temporal processing. Because degeneration of dopamine-producing cells of the $\mathrm{SNc}$ is a hallmark of $\mathrm{PD}$, a future imaging study of $\mathrm{PD}$ patients on these tasks would provide additional human evidence confirming the fundamental role of SNc in timing established by animal lesion work (Meck, 1996; Matell et al., 2000).

\section{References}

Brunia CH, de Jong BM, van den Berg-Lenssen MM, Paans AM (2000) Visual feedback about time estimation is related to a right hemisphere activation measured by PET. Exp Brain Res 130:328-337.

Buhusi CV, Meck WH (2005) What makes us tick? Functional and neural mechanisms of interval timing. Nat Rev Neurosci 6:755-765.

Casini L, Ivry RB (1999) Effects of divided attention on temporal processing in patients with lesions of the cerebellum or frontal lobe. Neuropsychology 13:10-21.

Corbetta M, Miezin FM, Dobmeyer S, Shulman GL, Petersen SE (1991) Selective and divided attention during visual discriminations of shape, color, and speed: functional anatomy by positron emission tomography. J Neurosci 11:2383-2402.

Dirnberger G, Frith CD, Jahanshahi M (2005) Executive dysfunction in parkinson's disease is associated with altered pallidal-frontal processing. NeuroImage 25:588-599.
Dreher J-C, Grafman J (2002) The roles of the cerebellum and basal ganglia in timing and error prediction. Eur J Neurosci 16:1609-1619.

Durvenoy HM (1991) The human brain: surface, blood supply, and threedimensional sectional anatomy. Vienna: Springer.

Ferrandez AM, Hugueville L, Lehericy S, Poline JB, Marsault C, Pouthas V (2003) Basal ganglia and supplementary motor area subtend duration perception: an fMRI study. NeuroImage 19:1532-1544.

Friston KJ, Ashburner J, Worsley KJ, Poline J-B, Frith CD, Heather JD, Frackowiak RSJ (1995a) Spatial registration and normalisation of images. Hum Brain Mapp 2:165-189.

Friston KJ, Holmes AP, Worsley KJ, Poline J-B, Frith CD, Frackowiak RSJ (1995b) Statistical parametric maps in functional imaging: a general linear approach. Hum Brain Mapp 2:189-210.

Friston KJ, Holmes AP, Price CJ, Buchel C, Worsley KJ (1999) Multisubject fMRI studies and conjunction analyses. NeuroImage 10:385-396.

Geyer S, Ledberg A, Schleicher A, Kinomura S, Schormann T, Buergel U, Klingberg T, Larsson J, Zilles K, Roland PE (1996) Two different areas within the primary motor cortex of man. Nature 382:805-807.

Geyer S, Schleicher A, Zilles K (1999) Area 3a, 3b, and 1 of human primary somatosensory cortex. 1. Microstructural organization and interindividual variability. NeuroImage 10:63-83.

Geyer S, Schormann T, Mohlberg H, Zilles K (2000) Areas 3a, 3b, and 1 of human primary somatosensory cortex. 2. Spatial normalization to standard anatomical space. NeuroImage 11:684-696.

Halsband U, Ito N, Tanji J, Freund HJ (1993) The role of premotor cortex and the supplementary motor area in the temporal control of movement in man. Brain 116:243-266.

Harrington DL, Haaland KY, Hermanowicz N (1998a) Temporal processing in the basal ganglia. Neuropsychology 12:3-12.

Harrington DL, Haaland KY, Knight RT (1998b) Cortical networks underlying mechanisms of time perception. J Neurosci 18:1085-1095.

Harrington DL, Boyd LA, Mayer AR, Sheltraw DM, Lee RR, Huang M, Rao SM (2004a) Neural representation of interval encoding and decision making. Cogn Brain Res 21:193-205.

Harrington DL, Lee RR, Boyd LA, Rapscak SZ, Knight RT (2004b) Does the representation of time depend on the cerebellum? Effect of cerebellar stroke. Brain 127:561-574.

Hinton SC, Meck WH (2004) Frontal-striatal circuitry activated by human peak-interval timing in the supra-seconds range. Cogn Brain Res 21:171-182.

Hollerman JR, Schultz W (1998) Dopamine neurons report an error in the temporal production of reward during learning. Nat Neurosci 1:304-309. 
Ivry RB (1996) The representation of temporal information in perception and motor control. Curr Opin Neurobiol 6:851-857.

Ivry RB, Keele SW (1989) Timing functions of the cerebellum. J Cogn Neurosci 1:136-152.

Ivry RB, Keele SW, Diener HC (1988) Dissociation of the lateral and medial cerebellum in movement timing and movement execution. Exp Brain Res 73:167-180.

Jahanshahi M, Jenkins IH, Brown RG, Marsden CD, Passingham RE, Brooks DJ (1995) Self-initiated versus externally triggered movements. I. An investigation using measurement of regional cerebral blood flow with PET and movement-related potentials in normal and Parkinson's disease subjects. Brain 118:913-933.

Jahanshahi M, Dirnberger G, Fuller R, Frith CD (2000) The role of the dorsolateral prefrontal cortex in random number generation: a study with positron emission tomography. NeuroImage 12:713-725.

Jones CRG, Rosenkranz K, Rothwell J, Jahanshahi M (2004) The right dorsolateral prefrontal cortex is essential in time reproduction: an investigation with repetitive transcranial magnetic stimulation. Exp Brain Res 158:366-372.

Jueptner M, Rijntjes M, Weiller C, Faiss JH, Timmann D, Mueller SP, Diener HC (1995) Localization of a cerebellar timing process using PET. Neurology 45:1540-1545.

Jueptner M, Flerich L, Weiller C, Mueller SP, Diener HC (1996) The human cerebellum and temporal information processing-results from a PET experiment. NeuroReport 7:2761-2765.

Kawashima R, Okuda J, Umetsu A, Sugiura M, Inoue K, Suzuki K, Tabuchi M, Tsukiura T, Narayan SL, Nagasaka T, Yanagawa I, Fujii T, Takahashi S, Fukuda H, Yamadori A (2000) Human cerebellum plays an important role in memory-timed finger movement: an fMRI study. J Neurophysiol 83:1079-1087.

Kish SJ, Shannak K, Hornykiewicz O (1988) Uneven pattern of dopamine loss in the striatum of patients with idiopathic Parkinson's disease. Pathophysiologic and clinical implications. N Engl J Med 318:876-880.

Lejeune H, Maquet P, Bonnet M, Casini L, Ferrara A, Macar F, Pouthas V, Timsit BM, Vidal F (1997) The basic pattern of activation in motor and sensory temporal tasks: positron emission tomography data. Neurosci Lett 235:21-24.

Lewis PA, Miall RC (2002) Brain activity during non-automatic motor production of discrete multi-second intervals. NeuroReport 13:1731-1735.

Lewis PA, Miall RC (2003a) Brain activation patterns during measurement of sub- and supra-second intervals. Neuropsychologia 41:1583-1592.

Lewis PA, Miall RC (2003b) Distinct systems for automatic and cognitively controlled time measurement: evidence from neuroimaging. Curr Opin Neurobiol 13:250-255.

Lewis PA, Miall RC (2006) A right hemispheric prefrontal system for cognitive time measurement. Behav Processes 71:226-234.

Macar F, Lejeune H, Bonnet M, Ferrara A, Pouthas V, Vidal F, Maquet P (2002) Activation of the supplementary motor area and of attentional networks during temporal processing. Exp Brain Res 142:475-485.

Macar F, Anton J-L, Bonnet M, Vidal F (2004) Timing functions of the supplemenatry motor are: an event-related fMRI study. Cogn Brain Res 21:206-215.

MacDonald CJ, Meck WH (2004) Systems-level integration of interval timing and reaction time. Neurosci Biobehav Rev 28:747-769.

Malapani C, Rakitin B, Levy R, Meck WH, Deweer B, Dubois B, Gibbon J (1998) Coupled temporal memories in Parkinson's disease: a dopaminerelated dysfunction. J Cogn Neurosci 10:316-331.

Mangels JA, Ivry RB, Shimizu N (1998) Dissociable contributions of the prefrontal and neocerebellar cortex to time perception. Cogn Brain Res 7:15-39.

Maquet P, Lejeune H, Pouthas V, Bonnet M, Casini L, Macar F, Timsit BM, Vidal F, Ferrara A, Degueldre C, Quaglia L, Delfiore G, Luxen A, Woods R, Mazziotta JC, Comar D (1996) Brain activation induced by estimation of duration: a PET study. NeuroImage 3:119-126.

Matell MS, Meck WH (2000) Neuropsychological mechanisms of interval timing behaviour. BioEssays 22:94-103.

Matell MS, Meck WH (2004) Cortico-striatal circuits and interval timing: coincidence detection of oscillatory processes. Cogn Brain Res 21:139-170.

Matell MS, Chelius CM, Meck WH, Sakata S (2000) Effect of unilateral or bilateral retrograde 6-OHDA lesions of the substantia nigra pars compacta on interval timing. Soc Neurosci Abstr 26:650.7.
Meck WH (1996) Neuropharmacology of timing and time perception. Cogn Brain Res 3:227-242.

Meck WH (2006) Neuroanatomical localization of an internal clock: a functional link between mesolimbic, nigrostriatal, and mesocortical dopaminergic systems. Brain Res 1109:93-107.

Meck WH, Malapani C (2004) Neuroimaging of interval timing. Cogn Brain Res 21:133-137.

Michon JA (1985) The complete time experiencer. In: Time, mind and behaviour (Michon JA, Jackson JL, eds), pp 21-52. Berlin: Springer.

Nelson HC (1982) National adult reading test (NART): test manual. Windsor, UK: NFER-Nelson.

Nenadic I, Gaser C, Volz HP, Rammsayer T, Hager F, Sauer H (2003) Processing of temporal information and the basal ganglia: new evidence from fMRI. Exp Brain Res 148:238-246.

Nichelli P, Alway D, Grafman J (1996) Perceptual timing in cerebellar degeneration. Neuropsychologia 34:863-871.

O'Boyle DJ, Freeman JS, Cody FWJ (1996) The accuracy and precision of timing of self-paced, repetitive movements in subjects with Parkinson's disease. Brain 119:51-70.

Oikawa H, Sasaki M, Tamakawa Y, Ehara S, Tohyama K (2002) The substantia nigra in Parkinson disease: proton density-weighted spin-echo and fast short inversion time inversion-recovery MR findings. Am J Neuroradiol 23:1747-1756.

Oldfield RC (1971) The assessment and analysis of handedness: the Edinburgh Inventory. Neuropsychologia 9:97-113.

Pardo JV, Pardo PJ, Janer KW, Raichle ME (1990) The anterior cingulate cortex mediates processing selection in the Stroop attentional conflict paradigm. Proc Natl Acad Sci USA 87:256-259.

Pastor MA, Artieda J, Jahanshahi M, Obeso JA (1992a) Time estimation and reproduction is abnormal in Parkinson's disease. Brain 115:211-225.

Pastor MA, Jahanshahi M, Artieda J, Obeso JA (1992b) Performance of repetitive wrist movements in Parkinson's disease. Brain 115:875-891.

Pastor MA, Macaluso E, Day BL, Frackowiak RSJ (2006) The neural basis of temporal auditory discrimination. NeuroImage 30:512-520.

Paulesu E, Frith CD, Frackowiak RS (1993) The neural correlates of the verbal component of working memory. Nature 362:342-345.

Penhune VB, Zatorre RJ, Evans AC (1998) Cerebellar contributions to motor timing: a PET study of auditory and visual rhythm reproduction. J Cogn Neurosci 10:752-765.

Pouthas V, George N, Poline JB, Pfeuty M, Vandemoorteele PF, Hugueville L, Ferrandez AM, Lehericy S, Lebihan D, Renault B (2005) Neural network involved in time perception: an fMRI study comparing long and short interval estimation. Hum Brain Mapp 25:433-441.

Rammsayer TH (1993) On dopaminergic modulation of temporal information processing. Biol Psychol 36:209-222.

Rammsayer TH (1997) Are there dissociable roles of the mesostriatal and mesolimbocortical dopamine systems on temporal information processing in humans? Neuropsychobiology 35:36-45.

Rammsayer TH (1999) Neuropharmacological evidence for different timing mechanisms in humans. Q J Exp Psychol B 52:273-286.

Rao SM, Harrington DL, Haaland KY, Bobholz JA, Cox RW, Binder JR (1997) Distributed neural systems underlying the timing of movements. J Neurosci 17:5528-5535.

Rao SM, Mayer AR, Harrington DL (2001) The evolution of brain activation during temporal processing. Nat Neurosci 4:317-323.

Rubia K, Overmeyer S, Taylor E, Brammer M, Williams S, Simmons A, Andrew C, Bullmore E (1998) Prefrontal involvement in "temporal bridging" and timing movement. Neuropsychologia 36:1283-1293.

Schmahmann JD, Doyon J, Toga AW, Petrides M, Evans AC (2000) MRI atlas of the human cerebellum. San Diego: Academic.

Schubotz RI, von Cramon DY (2001) Functional organization of the lateral premotor cortex: fMRI reveals different regions activated by anticipation of object properties, location and speed. Cogn Brain Res 11:97-112.

Schubotz RI, Friederici AD, von Cramon D (2000) Time perception and motor timing: a common cortical and subcortical basis revealed by fMRI. NeuroImage 11:1-12.

Talairach J, Tournoux P (1988) Co-planer stereotaxic atlas of the human brain: 3-dimensional proportional system: an approach to cerebral imaging. Stuttgart, Germany: Thieme.

Tracy JI, Faro SH, Mohamed FB, Pinsk M, Pinus A (2000) Functional localization of a "Time Keeper" function separate from attentional resources and task strategy. NeuroImage 11:228-242. 